\title{
SENSITIVITY OF EXHAUST-AIR FAÇADE PERFORMANCE PREDICTION TO MODELLING APPROACHES IN IDA ICE
}

\author{
A. GELESZ ${ }^{1,2}$ \\ ${ }^{1}$ Budapest University of Technology and Economics, Csonka Pál Doctoral School \\ ${ }^{2}$ ABUD Engineering, Ltd. \\ E-mail: gelesz.adrienn@abud.hu
}

Double skin façades are façade technologies that have the perspective of reducing energy use and improving comfort in buildings due to their adaptable nature. Exhaust-air façades offer the possibility to utilize solar energy by recovering heat from the façade cavity. However, the cavity overheating can be detrimental on the summer performance. Predicting performance and optimizing the system during the design phase is a challenge, especially when the cavity-air is integrated into the HVAC system. Whole-building energy simulation (BES) software tools are an adequate tool for calculating whole building performance, although these can have limitations in the accurate replication of complex building elements. The paper analyses the available and applied modelling approaches within a BES tool, and compares the outputs in terms of cavity temperature, horizontal and vertical temperature profiles, and heat flux through the façade. The sensitivity of the results on the modelling approach is evaluated. Results can serve as a guide for practitioners on the selection of the modelling approach for a given task.

Keywords: double skin façades, exhaust-air façade, building energy simulation, air-flow network, comparative modelling

\section{Introduction}

Double skin façades (DSFs) are façade elements that consist of two glazed skins and an intermediate cavity in which the possibility of air flow is given due to openings, driven by mechanical or natural forces. DSFs are considered façade technologies that can contribute to energy use reduction and improve occupant comfort, as they can provide a flexible and adaptable barrier between internal and external environment, due to their movable and controllable openings and shading elements. A recent meta-analysis shows that heating and cooling load reduction potential covers a broad range, from $90 \%$ of energy reduction potential down to an adverse increment of $30 \%$ or more [1]. There are many types of DSFs [2] with different features, based on their geometry, ventilation mode and airflow mode.

The prediction of DSF performance is key for integrating them into real buildings, especially for DSF types which do not only serve as a barrier between indoor and outdoor environment but can be connected to the HVAC system. During design phase, whole-build- ing energy simulation (BES) tools are popular and adequate tools for predicting whole building energy performance. However, as the focus of BES tools is on the evaluation of energy loads of an entire building [3], considering interaction of various parts, these tools can have limitations in the accurate replication of system behaviour for complex, less conventional building elements. Some BES tools include dedicated models for DSF systems (e.g. EnergyPlus, IDA ICE), including predefined features to model these phenomena; while DSF modelling in others is possible by creating a thermal and airflow network fit for the actual situation [4]. A recent research on the validation of the built-in models of two BES tools was carried out [5], showing some deviation between the simulation and experimental data.

This paper explores what modelling approaches exist for modelling exhaust-air DSF systems in IDA ICE, a BES tool that includes a dedicated model, and also the possibility of constructing a thermal-airflow model. Sensitivity of selected outputs is then compared in respect to the modelling approach. The results can serve as guidance for practitioners to select

Open Access statement. This is an open-access article distributed under the terms of the Creative Commons Attribution 4.0 International License (https://creativecommons.org/licenses/by/4.0/), which permits unrestricted use, distribution, and reproduction in any medium, provided the original author and source are credited, a link to the CC License is provided, and changes - if any - are indicated. (SID_1) 
the modelling approach best fit for their task, and also help choosing models during calibration and validation projects.

\section{Exhaust-air DSF systems}

The ventilation type of the DSF cavity can be either natural or forced, and based on the origin and destination of the air there can be 6 types of airflow concepts/modes [6]. The many types of DSF systems are summarized in Gelesz et al. [2]. The cavity of the exhaust-air façade is partitioned both vertically and horizontally, resulting in juxtaposed storey-high façade elements (Fig. 1). Elements are ventilated mechanically, in indoor air curtain/air exhaust mode, which means air typically enters from the lower region of the façade through an opening in the frame and leaves through a duct connected to the cavity at the upper part of the façade.

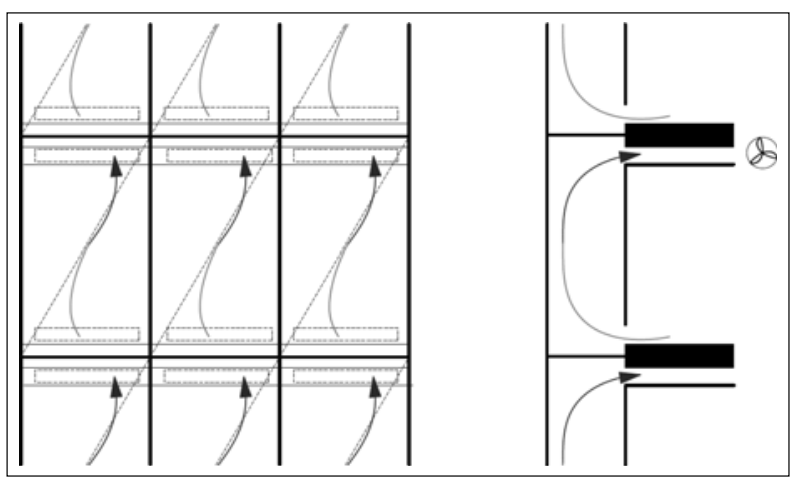

Fig. 1. View and section of an exhaust-air façade [2]

Exhaust-air façade systems are used in various parts of Europe, e.g. Belgium [7, 8], Italy [9-11]. Advantages of exhaust-air façades are the following:

- increased thermal performance as the room air is extracted through the façade;

- inside façade surface temperatures are higher in winter than in case of a single skin double glazed façade, which reduces radiant temperature asymmetry in the space;

- cavity air temperature is equal to or higher than the outdoor air - heat from solar radiation or transmission losses can be utilized by the HVAC systems locally or centrally by a heat recovery system;

- façades can be constructed with low cavity depth $(>14 \mathrm{~cm})$. Due to the compact geometry they can be constructed as prefabricated elements, and the reduction of the usable office space is low [12];

- movable shading is protected from weather, which makes it possible to operate them also at high wind situations, therefore improving the duration of operation;
- better sound attenuation of noise from the outside compared to a single skin façade.

There are also some challenges that need to be addressed:

- high glazing temperatures may occur in periods of high solar irradiation - if heat is not properly expelled, e.g. when ventilation is switched off;

- maintenance and cleaning is possible from the inside, through operable window sashes, which influences the furniture arrangement in an office space [12];

- increased installation and maintenance cost compared to a single skin façade.

\subsection{Modelling exhaust-air DSFs}

The modelling of DSFs is a complex task due to the thermophysical behaviour of DSF systems, depending on different transient heat transfer phenomena in opaque and transparent elements (short-wave transmission, absorption and reflection through transparent elements, multiple reflections through shading elements, long-wave absorption and reflection, heat conduction); mass transfer (airflow) due to a forced or natural ventilation driven by buoyancy and wind effects; and heat transfer between solids and air.

DSF performance prediction can be done by numerical approaches of different levels of complexity $[4,13,14]$. BES tools typically incorporate an approach where two equivalent networks: the thermal and the airflow networks are integrated. As Catto Lucchino, et al. [4] conclude, this is more detailed than using a single model based on empirical correlations and much less detailed than computational fluid dynamics (CFD). According to the authors, the approach has a trade-off between simulation time and complexity and therefore has some limitations: these models still rely on empirical correlations in some aspects (especially to solve equations of the mass transport and convective heat transfer), but include rather detailed information on the thermophysical properties and geometrical feature of the components of the DSFs (glazing systems, shading devices, openings, etc.). The precision of the models can be improved by calibration, however, there is a lack of comprehensive, freely available data set for this.

The main advantage of the integrated thermal and airflow network approach compared to e.g. CFD is that it needs computational time that is not too demanding, while it can calculate performance over a longer period, and also can incorporate options for controls, which is an important feature of adaptive façades. As the model can account for various geometrical and material properties and different airflow modes, it is an appropriate tool for practitioners, who need to com- 
pare performance of DSF alternatives within a timeframe fitting into the tight project deadlines, during not only preliminary, but also later design phases.

\subsection{Modelling option}

IDA ICE [15] is a commercially available whole-building simulation software used for predicting and optimizing heating loads, cooling loads, energy consumption and thermal comfort in buildings, and calculates the dynamic interaction between the ambient climate, the building, the building system and the building occupants. Solar loads and shading calculations are performed using ray tracing algorithms with consideration of surface reflection, venetian blinds, advanced shading control, including different optical parameters for different spectral bands [16]. The detailed window model makes a layer by layer computation of multiple reflections and each layer temperature is computed, and also can simulate ventilated double skin façade and other complex glass facades in accordance with ISO 15099 [17]. The detailed window model also includes a capacity node for the glazing and the shading, which is not present in many BES tools [13]. Wind and buoyancy driven airflows through leaks and openings can be calculated via a fully integrated airflow network model [18]. IDA ICE 4.8 SP1 is the most recent version and is used on this task.

There are two main approaches for modelling DSFs within the tool:

- the built-in component (ventilated window model, $v w m$ )

- or the façade can be constructed tailor-made consisting of one or more connected thermal zones.

The schematics of the components and links in the models is seen in Fig. 2.

The $v w m$ allows defining characteristics of the DSF directly through a dedicated graphical interface. The model consists of two detailed window models representing the two transparent skins, possibly including shadings; air inlet and outlet components towards the internal, external or the HVAC systems; and a custom component for the ventilated cavity. Openings can be defined towards the indoor environment and to the outside, additionally, a forced flow rate can be given to the HVAC system. No enclosing elements around the cavity are considered in the calculation, except for the façade elements (glazing, frames, shading) parallel to the façade [19].

Modelling as an airflow network can be done using zones, openings, etc. also through the graphical interface for most geometries. In this case zones will represent the cavity; the glazed skins need to be added by the modeler. Using this method results in longer modelling process, but also allows more flexibility.
It is possible to divide the façade cavity into multiple zones and connect them through leaks or openings. There is no standard approach when it comes to the ideal number of zones, these usually range from a minimum of one thermal zone up to a maximum of six (referred to one-storey DSF) [4]. In this case the zone model already includes the model of the enclosing elements perpendicular to the façade plane, which are neglected in the built-in model. Heat transfer, absorption of long-wave and solar radiation, airflow is possible through these surfaces and also shortwave reflection from these surfaces is taken into account.

When following either approach, the shading layer needs to be modelled as part of any one or the other detailed window. The air gap that is between the shading and the window it is linked to is not part of the cavity airflow network. This is a simplification of the air-flow patterns seen in reality (e.g. [8]), where both cavities are ventilated to some extent.

When modelling with multiple zones, leaks, that allow airflow only, and openings, that allow both airflow and radiation to pass through need to be configured to connect the sections of the cavity. There is, however, one limitation in the Standard edition: walls, ceilings, and floors that are smaller than $0.5 \mathrm{~m}^{2}$ will be ignored in the model, which might apply in the case of DSFs with narrow cavities, typical for exhaust-air facades. In this case the connections can be configured in the Expert edition (advanced level). While configuring airflow connections manually at the advanced level is straightforward, interacting with the radiation model is very difficult. The reason for this is that at the beginning of the calculation the actual shading factors are precomputed for all (plausible) solar locations and are stored as parameters in the shade model connected to each window/opening. [18] Each value is subjected to several coordinate transformations, hence modifying and extending this set of data is a complex task, not viable during a standard design project.

As described in the user manual, the fraction of radiation reaching each window and surface is calculated, both for diffuse and direct radiation, with the help of the Shading, Winlight, Lightfract models. In the $v w m$ there are no surfaces reflecting or absorbing the radiation in the cavity, except for the windows. In the zone models the radiation to the enclosing surfaces and openings is calculated. Once the radiation hits a window, the whole surface of the window is considered as the radiation source, not just the portion of the glass which is actually not shaded by external objects. After the first reflection on a zone surface, the direct beam is spread diffusely in the room, while the exact target location of the direct light beam is computed. The whole surface that is hit is regarded to reflect with equal intensity, not just the lit portion of this surface [18]. 

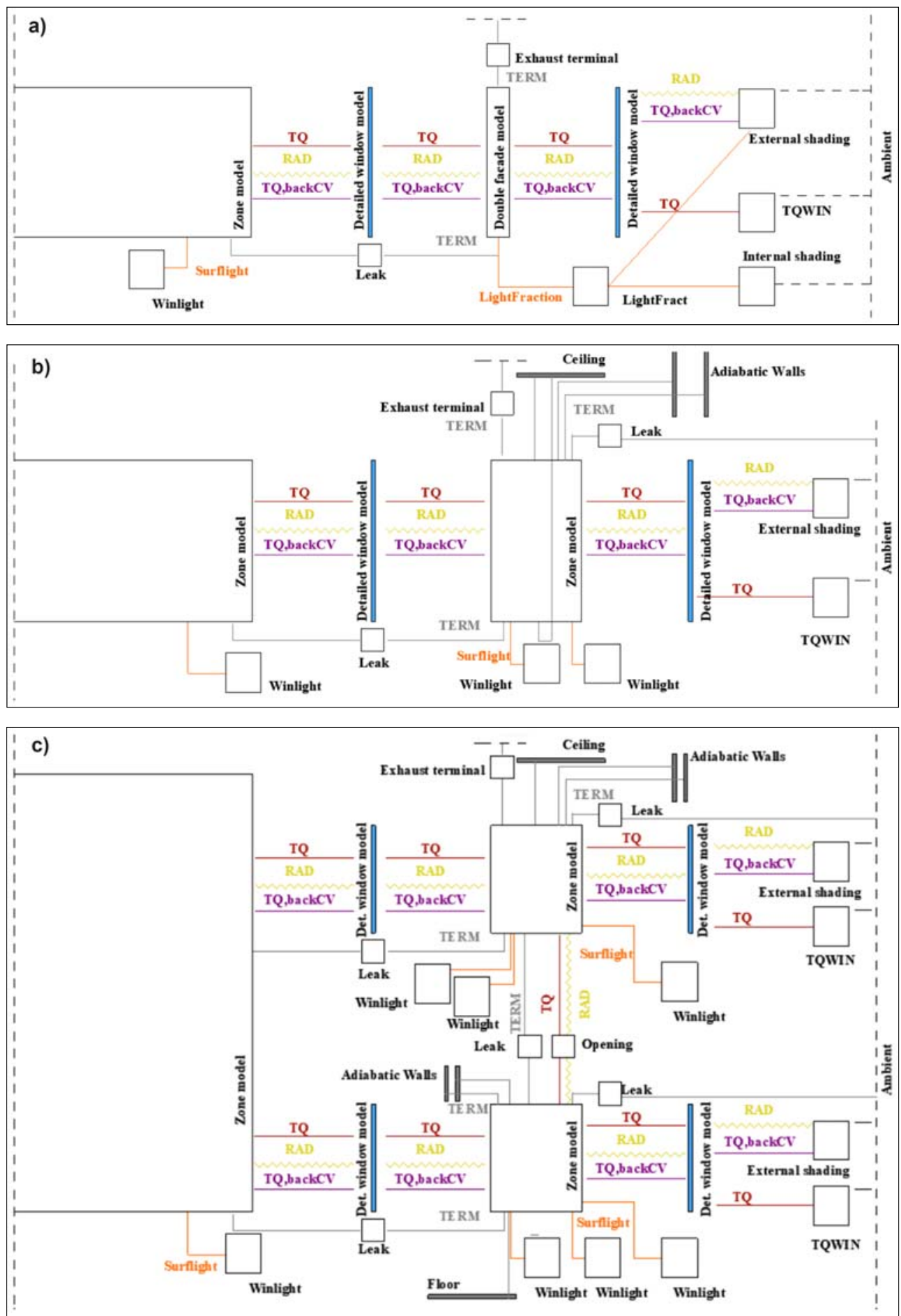

Abbreviations:

\section{Connection types:}

TQ - Heat flow (incl. temperature data for long wave rad.)

RAD - Solar radiation

TQ, backCV - Heat flow from back convection behind shade

TERM - Bidirectional air flow

LightFract: Fraction of light to subsurface

Surflight: Light distribution coefficients
Models:

TQWIN: Window exterior surface exposed to long-wave radiation and convection

LightFract: Calculates fraction of light to subsurface

Winlight: Calculates light distribution between surfaces in zone

Fig. 2. Schematic of the models: a) built-in model b) 1-zone model c) 2 zones connected via openings 
Table 1. Equations used for calculating convective heat transfer coefficients within the ventilated window model

\begin{tabular}{|c|c|c|c|}
\hline \multicolumn{2}{|c|}{ Natural flow (DNCA) } & \multicolumn{2}{|r|}{ Forced flow } \\
\hline $\begin{array}{l}\text { If } \Delta T<0^{\circ} \mathrm{K} \text { and surface } \\
\text { slope }<90^{\circ}\end{array}$ & $\begin{array}{l}h_{\text {nat, conv }} \\
\quad 9.482|\Delta T|^{1 / 3}\end{array}$ & \multicolumn{2}{|c|}{$h_{\text {conv, forced }}=N u(\lambda / l)$} \\
\hline $\begin{array}{l}\text { Or } \Delta T>0^{\circ} \mathrm{K} \text { and surface } \\
\text { slope }>90^{\circ}\end{array}$ & $=\overline{7.823-|\cos (\pi[\beta / 180])|}$ & \multicolumn{2}{|c|}{$\operatorname{Re}=l v(\rho / \eta)$} \\
\hline \multirow[b]{2}{*}{ Else } & $h_{\text {nat, conv }}$ & $\begin{array}{l}\text { if } \operatorname{Re}<10^{4} \\
\text { (laminar flow) }\end{array}$ & $N u=0.664 \operatorname{Re}^{1 / 2} \cdot \operatorname{Pr}^{1 / 3}$ \\
\hline & $=\frac{1.81|\Delta T|^{1 / 3}}{1.382+|\cos (\pi[\beta / 180])|}$ & $\begin{array}{l}\text { if } \operatorname{Re}>10^{4} \\
\text { (turbulent flow) }\end{array}$ & $N u=\frac{0.037 \operatorname{Re}^{0.8} \operatorname{Pr}}{1+2.443 \operatorname{Re}^{-0.1}\left(\operatorname{Pr}^{2 / 3}-1\right)}$ \\
\hline
\end{tabular}

where:

$v$ - air speed $[\mathrm{m} / \mathrm{s}]$

$l$ - height of cavity $[\mathrm{m}]$

$\eta$ - dynamic viscosity of the air $\left[\mathrm{N} \mathrm{s} / \mathrm{m}^{2}\right]$

$\rho-$ air density $\left[\mathrm{kg} / \mathrm{m}^{3}\right]$

For the ventilated window model, the equation for $h_{\text {conv }}$ is chosen from the greater of the convective heat transfer coefficient resulting from natural and forced airflow; regardless of the modelled driving forces in the model:

$$
h=\max \left(h_{\text {conv, forced }} ; h_{\text {nat, conv }}\right) \text {. }
$$

The forced convection heat transfer function is taken from the VDI Heat Atlas [20]. First the Reynold's number is calculated, that is used then to calculate the Nusselt number. Both laminar flow and turbulent flow can be considered, depending on the cavity geometry and air speed. The calculation method of the natural convection follows the Detailed Natural Convection Algorithm (DNCA), depending on the temperature difference of the surface and the air, and also the inclination of the surface (surface slope $=0$ for floor and 180 for ceiling) (Table 1).

In the zone model the convective heat transfer coefficient can be selected from several options (Table dependent on $\Delta T$, Simple Natural Convection Algorithm (SNCA), Ceiling Diffuser Algorithm (CDA), DNCA, user defined constant). The default value for the convective heat transfer coefficient is based on the maximum of the predefined table values within the $u$ film function, or the following equation (CDA):

$$
h_{\text {conv }, \mathrm{CDA}}=1.208+1.012 \max (0.0, \mathrm{ACH})^{0.604} \text {. }
$$

\section{Model setup}

A model with one zone representing a room is created, with one South oriented DSF, modelled following the different options detailed below. The internal structures of the room are set adiabatic and shortwave

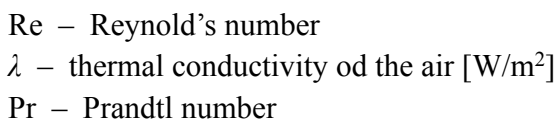

reflection from those is neglected. The DSF has a mechanically ventilated cavity with $0.22 \mathrm{~m}$ depth, where the indoor air flows into the cavity from a bottom opening and it is then extracted through a duct, placed at the top of the ventilated cavity. The total façade width is $3.20 \mathrm{~m}$ and the height is $3.40 \mathrm{~m}$. The inside skin consists of a single pane glazing, and the outside skin is constructed of low-iron glass with selective coating (Table 2). Frame properties are set to $10 \%$ frame ratio on both internal and external skins, with a heat transfer coefficient of $U_{\text {frame }}=2 \mathrm{Wm}^{2} \mathrm{~K}$. A single setpoint for each season is given for indoor temperature and supply air temperature $\left(20^{\circ} \mathrm{C}\right.$ in winter, $26^{\circ} \mathrm{C}$ in summer). The DSF is ventilated with Constant Air Volume system, with a flow rate of $12.5 \mathrm{~m}^{3} / \mathrm{h}$ of each façade $m$, while the zone representing the indoor space is ventilated with an airflow rate equalling the total air exhausted from the DSF. The simulations are done in two configurations, one with shading and one without shading. The shading system is a highly reflective roller blind placed at $7 \mathrm{~cm}$ from the exterior glazing unit, integrated in the external skin as a baseline, but the effect of integrating it into the internal skin is also analysed.

In the case of modelling with multiple zones, the zones are connected via horizontal leaks/openings covering the total cavity section, that are always open, $C_{d}=1$. The shortwave surface reflectance values of the enclosures perpendicular to the façade plane are set to 0.5 . The structures horizontally dividing the cavity are modelled using fictious materials, that are $1 \mathrm{~mm}$ thin and have very low $(0.001 \mathrm{~J} / \mathrm{kgK})$ heat capacity.

Whole year simulations are run, using Torino weather data.

The following models are created and compared (Table 3): 
Table 2. Glazing and shading configurations, solar optical and thermophysical properties $\left(T_{\text {sol,out }}:\right.$ solar transmittance at the outside of the glazing, $R_{\text {sol,out }}$ : solar reflection at the outside of the glazing, $R_{\text {sol,in }}$ : solar reflection at the inside of the glazing)

\begin{tabular}{|c|c|c|c|c|c|c|c|}
\hline & & ayers from exterior to interior & $T_{\text {sol, out }}$ & $R_{\text {sol, out }}$ & $R_{\mathrm{sol}, \text { in }}$ & $\begin{array}{l}U \text {-value* } \\
{\left[\mathrm{W} / \mathrm{m}^{2} \mathrm{~K}\right]}\end{array}$ & $g$-value* \\
\hline Internal skin & $10 \mathrm{~mm}$ & Laminated clear glass 5.5.4 & 0.7 & 0.066 & 0.066 & 5.59 & 0.788 \\
\hline \multirow[t]{3}{*}{ External skin } & $20 \mathrm{~mm}$ & $\begin{array}{l}\text { Laminated, low-iron glass with } \\
\text { selective coating, pos. } 2,10.10 .4\end{array}$ & \multirow{3}{*}{0.323} & \multirow{3}{*}{0.307} & \multirow{3}{*}{0.45} & \multirow{3}{*}{1.357} & \multirow{3}{*}{0.379} \\
\hline & $16 \mathrm{~mm}$ & Air & & & & & \\
\hline & $10 \mathrm{~mm}$ & Low-iron clear glass & & & & & \\
\hline Blind & & High reflectance roller blind & 0.1 & 0.8 & 0.8 & - & - \\
\hline
\end{tabular}

*At reference conditions defined by ISO 15099:2003.

Table 3. DSF models compared

1 DSF module;
Shading integrated in the
external skin, when present

- One-storey high façade element modelled as a ventilated window model $(v w m)$

- DSFs modelled as zones models:

one-storey high zone (1 zone)

○ 2 zones per storey, $1.7 \mathrm{~m}$ each ( 2 zones)

○ 3 zones per storey, $1.13 \mathrm{~m}$ each (3 zones)

$\circ 6$ zones per storey, $0.565 \mathrm{~m}$ each (6 zones)

In reality, the typical construction of this façade geometry would be two juxtaposed modules, $1.6 \mathrm{~m}$ wide each. However, as previously described, for the zone models, the area of the horizontal partitions $\left(0.352 \mathrm{~m}^{2}\right)$ is too small to allow the modelling of the connections with openings. Hence, as a first step, the DSF element covers the whole facade (Version A), and as a next step, two $1.6 \mathrm{~m}$ wide DSFs are modelled (Version B), and connected with a custom generated airflow network without reconstructing the radiation model (Table 3).

\section{Results}

The results for two representative periods are shown, solar radiation and temperatures can be seen in Fig. 3. Average cavity temperatures, horizontal temperature profiles and vertical temperature profiles are com-

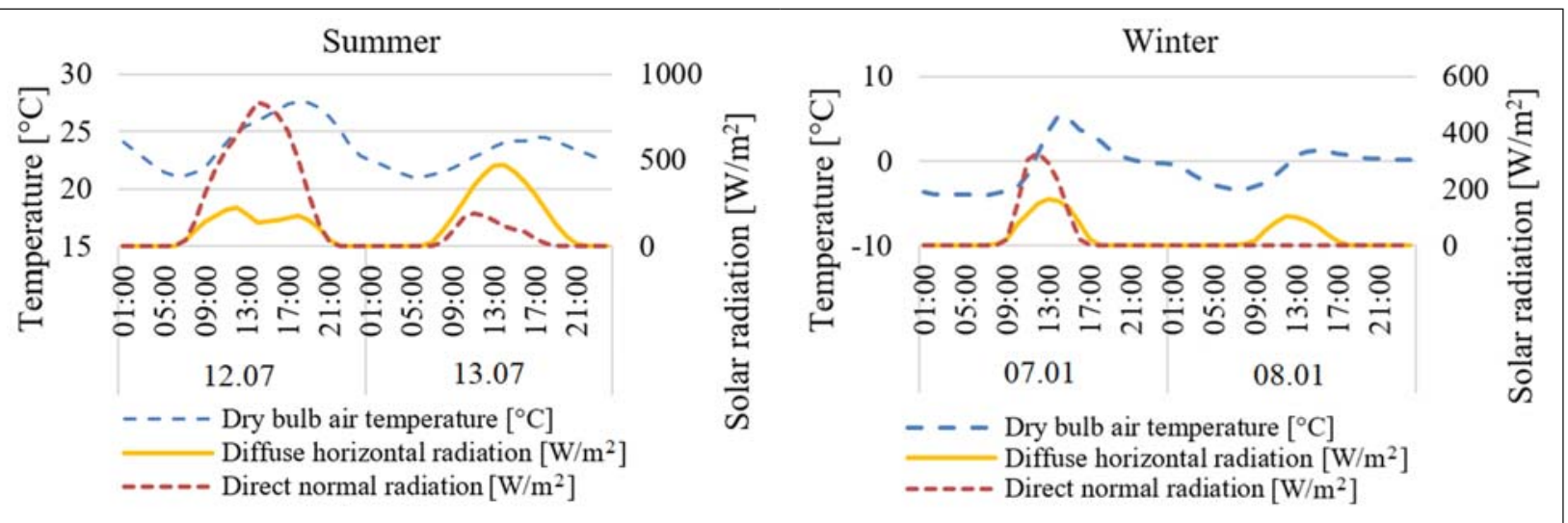

Fig. 3. Weather data of the selected periods 


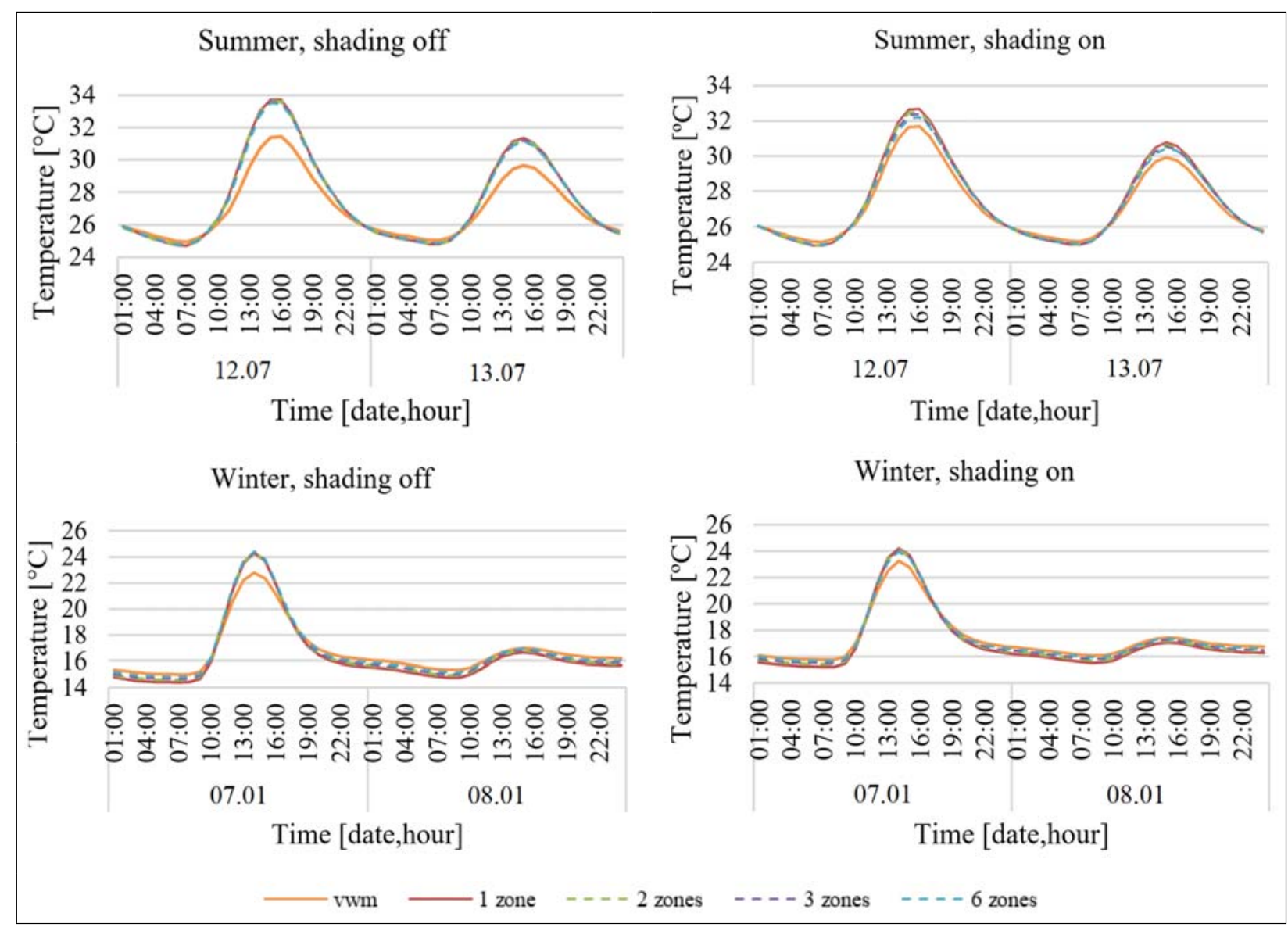

Fig. 4. Average cavity temperatures - Version A

pared, as well as solar radiation and total heat transferred through the façade element. Also, simulation time, and convective heat transfer coefficients are plotted and compared.

\subsection{Average cavity temperatures}

Cavity-air temperatures are taken from the cavity/zone air nodes, and in the case of multiple zones stacked upon each other, the single values are calculated by averaging the results of all connected zones. At peri- ods with solar radiation, values for the $v w m$ are the lowest, while at winter night periods the $v w m$ has the highest temperatures.

In Version $\mathrm{A}$, the number of zones has a low effect on the results, the highest variation is in the case of summer, shading on, when the 1-zone mod$\mathrm{el}$ is maximum $0.5^{\circ} \mathrm{C}$ higher than the 6-zone model (Fig. 4). The highest differences are between the $v w m$ and the 1-zone model, $2{ }^{\circ} \mathrm{C}$, when shading is off, and $1{ }^{\circ} \mathrm{C}$ when shading is down in summer; while $0.6^{\circ} \mathrm{C}$ at winter night.

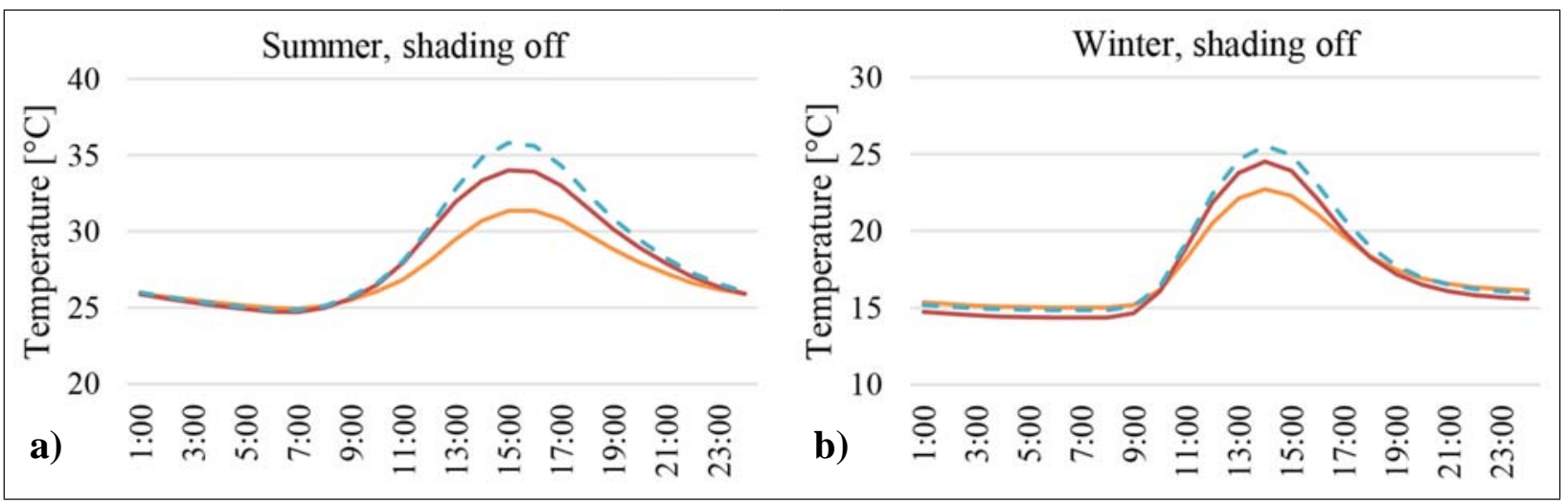

Fig. 5. Average cavity temperatures - Version B: a) 12.07., b) 07.01 . 


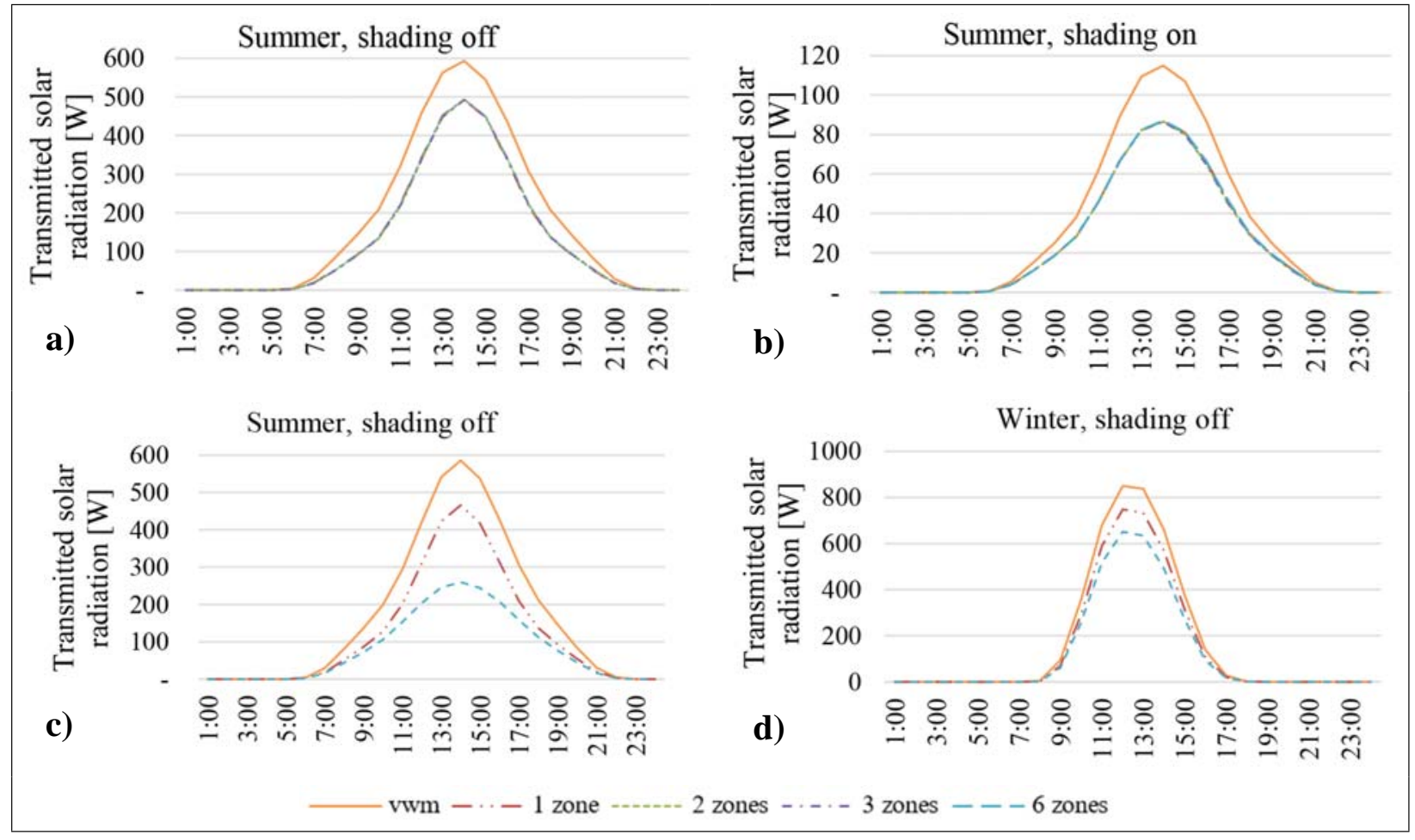

Fig. 6. Transmitted net solar radiation - Version A: a) 12.07., b) 12.07, Version B: c) 12.07., d) 07.01.

In Version B, the number of zones has a more pronounced effect on the results, causing an increase in the differences between the zone models and the $v w m$
(Fig. 5). In this case, the 6-zone model has the highest difference, reaching up to $4.1{ }^{\circ} \mathrm{C}$ in summer, with shading off.

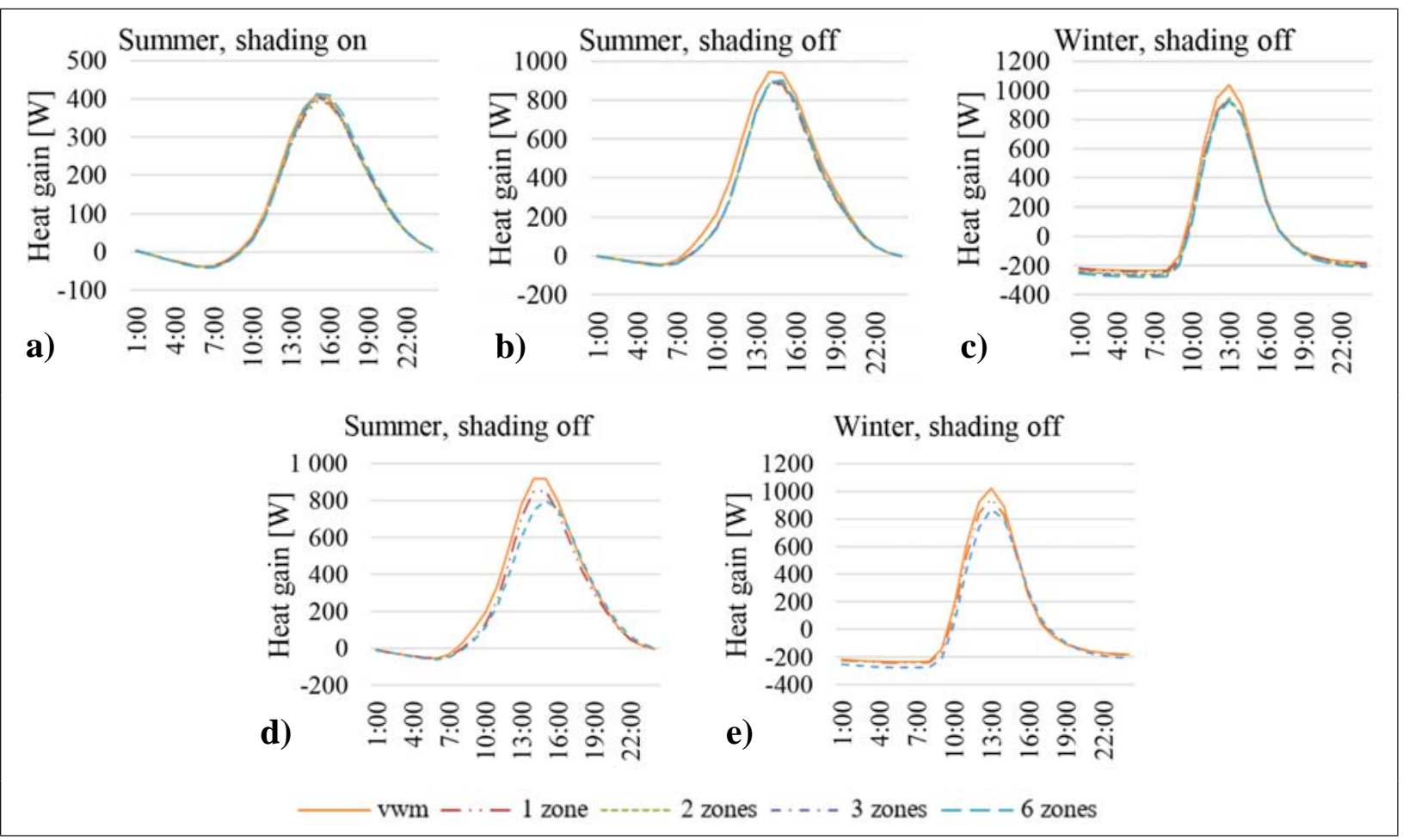

Fig. 7. Total heat transmitted through the whole façade: Model A: a) 12.07., b), 12.07., c) 07.01., Version B: d) 12.07., e) 07.01. 


\subsection{Net solar radiation}

The results for the net solar radiation to the zone, calculated at the surface of the interior skin shows that the highest values result in the case of the $v w m$ in all cases. The difference between the $v w m$ and zone modelling approaches is higher when the shading is on and lower when it is off ( $25 \%$ and $17 \%$ at peaks, respectively). In Version A (Fig. 6a and b) the number of zones does not affect the total net solar radiation, while in Version B (Fig. 6c and d) the difference reaches up to $60 \%$.

\subsection{Heat transfer through the façade}

Heat transmitted through the façade elements are calculated as the sum of transmitted net solar radiation + convective heat and longwave radiation transferred from all elements to the zone at the inside glazing (Fig. 7). The time profiles of the different models are aligned for Version A, while some shift is seen in the peaks for Version B. The deviation of the values is within $15 \%$ for both minimum and maximum values, for both Versions A and B. As seen for the solar radi- ation as well, the values for Version $\mathrm{A}$ are aligned regardless of the number of zones, while for Version B the results differ depending on the number of zones. The highest gains can be seen for the $v w m$, while the highest losses are for the 6-zone model.

\subsection{Horizontal temperature profiles}

From the layer-by-layer calculation in the model, the results representing the temperature of each node for solid elements, surfaces and air can be plotted for any time step. Figure 8 shows the results at peak summer weather conditions. The profiles are compared when modelled as one-storey high element for both the $v w m$ and the zone approach (Version A), also comparing results with the shading linked to the internal or external skin.

The differences of the surface temperatures of the internal skin are within $1{ }^{\circ} \mathrm{C}$ for the different modelling approaches. With shading off, the highest deviation is seen for the cavity air temperature $\left(2^{\circ} \mathrm{C}\right)$. With shading when the shading is connected to the external skin (Fig. 8b, solid lines), the results of the vwm and the

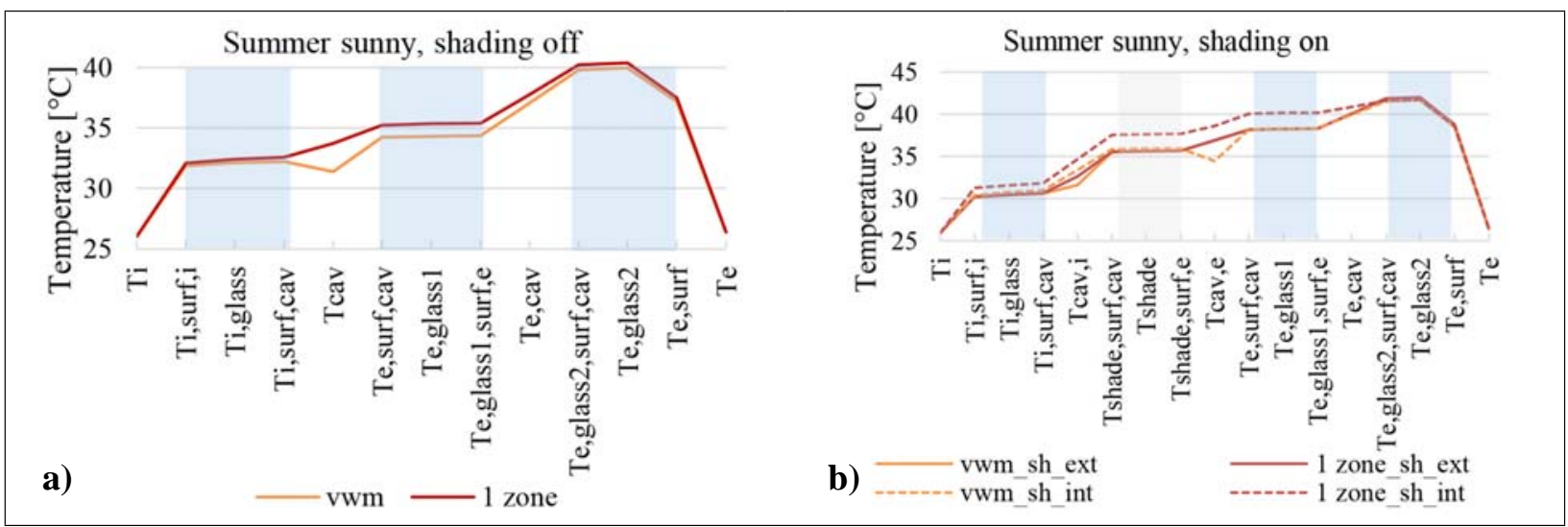

Fig. 8. Horizontal temperature profiles through the façade for a summer, sunny hot day (12.07., 15:00); a) shading off b) shading on; sh_ext = shading linked to the external skin, sh_int = shading linked to the internal skin, Version A

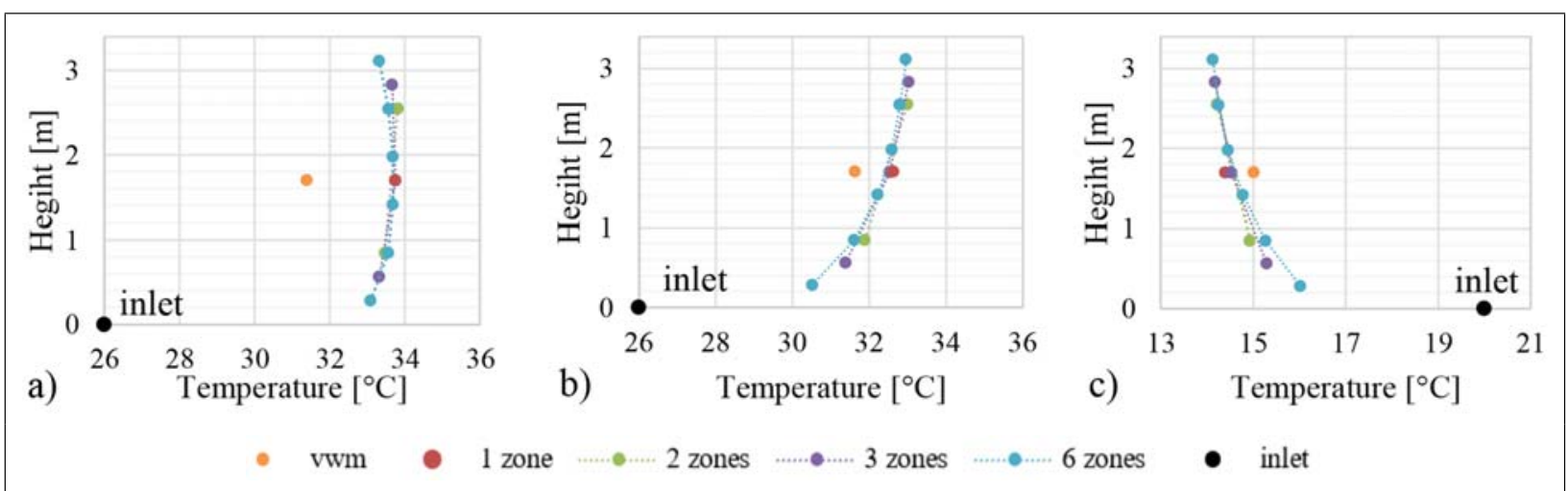

Fig. 9. Vertical temperature profiles resulting of different modelling methods (A): a) 12.07.16:00; Summer sunny peak, shading off b) 12.07.16:00, Summer sunny peak, shading on c) 07.01.7:00, winter night, shading off 
zone model are aligned, while in case it is linked to the internal skin (Fig. 8b, dashed lines) the difference reaches up to $4^{\circ} \mathrm{C}$ in the external cavity.

\subsection{Vertical temperature profiles}

Figure 9 shows the vertical temperature profiles of the internal cavity of the façade model under two representative boundary conditions, shading on and off. Points are placed in the middle of the zone on the vertical axis and represent the average values for each zone.

All zone models approximate a similar temperature profile, while the single value for the temperature in the $v w m$ in neither case matches that profile, being lower in summer and higher in winter. With modelling with multiple zones some stratification effect is seen, although the difference of the single temperature of the 1-zone DSF and the output temperature of the 6-zone model is low, within $0.4^{\circ} \mathrm{C}$.

\subsection{Convective heat transfer coefficients}

Table 4 shows the convective heat transfer coefficients $\left(h_{\text {conv }}\right)$ and dimensionless numbers calculated over the whole year for three cases. The calculated $h_{\text {conv }}$ is the lowest in the case of the vwm and highest for the

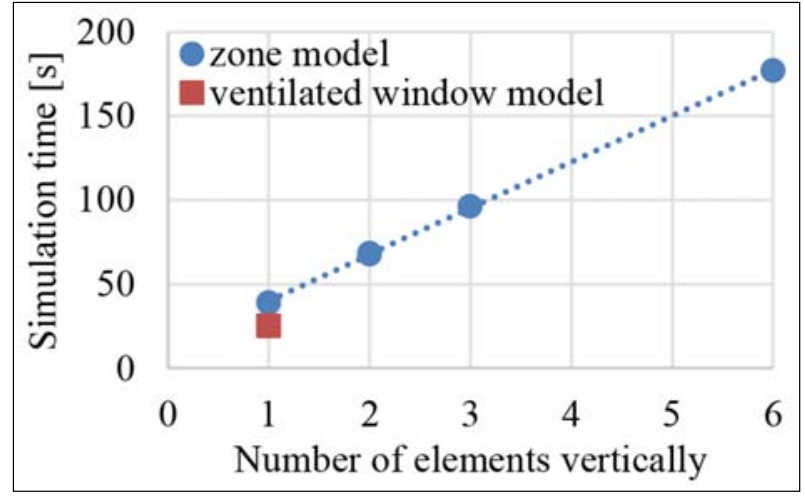

Fig. 10. Simulation time

6-zone model. The difference is one order of magnitude for the values. It can also be observed that the $v w m$ assumes laminar flow next to the skins, when calculating $h_{\text {conv, forced }}(\operatorname{Re}<10000)$. However, the $h_{\text {conv }}$ is eventually calculated based on natural flow, using the DNCA method more than $99 \%$ of the time.

\subsection{Simulation time}

The simulation time for the $v w m$ is the lowest. For zone models the relationship between the number of zones and the simulation time is linear (Fig. 8).

Table 4. Calculated values of convective heat transfer coefficients

\begin{tabular}{lcc}
\hline & \multicolumn{2}{c}{$h_{\text {conv }}\left[\mathrm{W} / \mathrm{m}^{2} \mathrm{~K}\right]$} \\
\cline { 2 - 3 } & \multicolumn{1}{c}{ Shading off } & Shading on \\
\hline$v w m$ & inside surface: $0.33-1.82$ & inside surface: $0.27-1.07$ \\
& outside surface: $0.29-2.14$ & outside surface: $0.37-2.43$ \\
\hline 1 zone & \multicolumn{2}{c}{$6.57-6.82$} \\
6 zones & $16.83-27.54$ \\
\hline
\end{tabular}

Table 5. Calculated values of convective heat transfer coefficients and dimensionless numbers, $v w m$

\begin{tabular}{cccc}
\hline$h_{\text {conv, nat }}\left[\mathrm{W} / \mathrm{m}^{2} \mathrm{~K}\right]$ & $h_{\text {conv, forced }}\left[\mathrm{W} / \mathrm{m}^{2} \mathrm{~K}\right]$ & $N u[-]$ & $\operatorname{Re}[-]$ \\
\hline $0.09-2.43$ & 0.27 & $34.32-34.52$ & $3356.6-3395.1$ \\
\hline
\end{tabular}

\section{Discussion}

The results for average cavity temperatures, heat gain through the façade show some differences due to the selected modelling approach. For average cavity temperatures, the $v w m$ results in the lowest average cavity temperatures at peak summer conditions, and the highest values at night without solar radiation, the difference between the models with $v w m$ and the zone approach being between $-0.7{ }^{\circ} \mathrm{C}-4.2{ }^{\circ} \mathrm{C}$. For the heat gain, the results for the configuration with shading on are well aligned, while differences are seen with shading off in the magnitude of $<15 \%$. The most sensitive KPI is the transmitted solar radiation, which shows differences up to $60 \%$ depending on the modelling method. This is due to the calculation method of the solar transmission and the different handling of the elements perpendicular to the façade plane. For models with multiple zones, the results of solar transmission show high sensitivity to whether the horizontal parti- 
tions allow radiation to pass through, or not. The lack of radiation transmission in the horizontal connections results in significantly lower transmitted solar radiation values, especially with high sun angles, where the values are $60 \%$ lower in the case of the 6 -zone model than the $v w m$. This has, however, a limited effect on the total heat gain through the façade $(<15 \%)$, which is due to the fact that the solar radiation not reaching the room is eventually transmitted as longwave radiation and convective/conductive heat.

The horizontal temperature profiles have low sensitivity to the $v w m / z o n e$ modelling method, however, the results are sensitive to which skin the shading is integrated in. When shading is present in the zone model, the integration of the shading in one or the other skin may cause temperature differences up to $4{ }^{\circ} \mathrm{C}$ within the external cavity, which is higher than the differences due to the modelling method.

From the vertical temperature profiles, it is seen that by modelling multiple zones, the stratification effect can be modelled to some extent, however, the exhaust temperature shows only a small difference when the number of zones is increased. The difference between the 1-zone model and the 6-zone model is within $0.4{ }^{\circ} \mathrm{C}$, and within $0.2{ }^{\circ} \mathrm{C}$ for the 2-zone model and the 6-zone, which is much lower than the difference due to $v w m / z o n e$ models $\left(2^{\circ} \mathrm{C}\right)$. While in the case of a one-storey high DSF, partitioning the cavity vertically does not have a high effect on the exhaust-air temperatures, the difference can be more pronounced in case the façade has an uninterrupted cavity covering several stories, which can affect the performance of the system in case the façade cavity is meant to be connected to the HVAC network for heat recovery.

The calculated convective heat transfer coefficient values show a high variation due to the different equations used in the models. Although the highest values (6-zone model, top zone) are more than $10000 \%$ higher than the lowest values $(\mathrm{vwm})$, the low difference in the cavity-air temperatures indicates that this variable has low effect on the results, as the model is configured with forced ventilation.

\section{Conclusion}

The possible modelling options of an exhaust-air façade have been analysed and evaluated. One of the popular tools (IDA ICE) for whole building energy simulation has been used, which includes a builtin model (ventilated window model) for DSFs in addition to the more conventional way of modelling, where DSFs are constructed element by element, as an airflow network. The built-in ventilated window model $(v w m)$ is compared to zone models, from one to 6-zones stacked upon each other, following two ways to model horizontal connections.
The differences in cavity temperature, heat gain and transmitted solar radiation results between the $v w m$ and different zone model approaches are in the order of magnitude of $4{ }^{\circ} \mathrm{C}, 15 \%, 60 \%$, respectively. The number of zones stacked upon each other has a low influence on the results, while the provision of radiation connections and the position of the shading, in terms of which skin it is linked to, has a higher effect.

When comparing zone models with multiple zones stacked upon each other, it is seen that eliminating radiation connections in the horizontal partitions which is a model limitation with narrow cavities - will have a notable effect on the cavity temperatures (up to $2{ }^{\circ} \mathrm{C}$ increase for a 6-zone model) and solar radiation ( $47 \%$ decrease for a 6 -zone model), while only a moderate effect on the overall heat transferred $(-13 \%$ for a 6-zone model). When radiation connections are also modelled in the partitions, increasing the number of zones does not have a high effect on the results, while the simulation time increases linearly. Hence, in case of one-storey high models, keeping the model simple is more reasonable.

From the results, it cannot be ascertained which modelling approach is more precise in prediction of performance, and it is a further task to provide a comparative validation for the approaches. However, the validation of the built-in model [5] shows that cavity-air temperatures are typically underestimated, while heat flux is close to the experimental values with shading down, and overestimated in times with shading up. This indicates that results from modelling as zones should be more reliable, although not in all cases. As a next step, the results should be validated to see the error range, and to define which modelling method is the most precise.

While the $v w m$ model is easy readily available and easy to configure, the zone model is more flexible, and has the advantage of being improved through additional features, when more detailed information, from experimental or CFD data is available for calibration:

- adding heating or cooling elements in the inlet and outlet region is more straightforward than in the case of the built-in model

- when using the climate mode for the zones, it is possible to add a temperature gradient for the cavity air, although this cannot be changed throughout the simulation time.

- adding the effect of thermal bridges and the solar reflection of enclosing elements (frame) is possible with the zone model.

\section{Acknowledgements}

Supported by the ÚNKP-18-3 New National Excellence Program of the Ministry of Human 
Capacities. The author is also grateful for the support of Advanced Building and Urban Design Engineering, Ltd., especially to Dr. Andras Reith.

\section{References}

[1] Pomponi F., Piroozfar P. A. E., Southall R., Ashton P., Farr E. R. P. (2016), Energy performance of double-skin façades in temperate climates: A systematic review and meta-analysis. Renew. Sustain. Energy Rev., 54, 15251536, http://dx.doi.org/10.1016/j.rser.2015.10.075

[2] Gelesz A., Reith A. (2011), Classification and re-evaluation of double-skin facades. Int. Rev. Appl. Sci. Eng., 2(2), 129-136, http://www.akademiai.com/openurl.asp?gen$\mathrm{re}=$ article \&id=doi:10.1556/IRASE.2.2011.2.9

[3] Oh S., Haberl J. S. (2016), Origins of analysis methods used to design high-performance commercial buildings: Whole-building energy simulation. Sci. Technol. Built Environ., 22(1), 118-137.

[4] Catto Lucchino E., Goia F., Lobaccaro G., Chaudhary G. (2019), Modelling of double skin facades in whole-building energy simulation tools: A review of current practices and possibilities for future developments. Build. Simul., 12(1), 3-27.

[5] Gelesz A., Catto Lucchino E., Goia F., Reith A., Serra V. (2019), Reliability and sensitivity of building performance simulation tools in simulating mechanically ventilated double skin facades. In: Proceedings of Building Simulation 2019: 16th Conference of IBPSA.

[6] Loncour X., Deneyer A., Blasco M., Flamant G., Wouters P. (2004), Ventilated double facades: classification \& illustration of facade concepts. no. October, p. 49, http://www. bbri.be/activefacades/new/download/Ventilated_Doubles Facades - Classification \& illustrations.dvf2 - final.pdf

[7] Schiefer Christian B. Å., Heimrath R., Hengsberger H., Mach T., Streicher W., Santamouris M., Farou I., Erhorn H., Erhorn-Kluttig H., de Matos M., Duarte R. (2005), Best practice for double skin façades WP 1 Report 'State of the Art'. http://www.bestfacade.com/pdf/downloads/ Bestfacade_WP1_Report.pdf.
[8] Saelens D. (2002), Energy performance assessment of single storey multiple-skin facades. no. September. http:// bwk.kuleuven.be/bwf/PhDs/PhDSaelens.

[9] Corgnati S. P., Perino M., Serra V. (2007), Experimental assessment of the performance of an active transparent facade during actual operating conditions. Sol. Energy, 81(8), 993-1013.

[10] Zanghirella F., Perino M., Serra V. (2011), A numerical model to evaluate the thermal behaviour of active transparent facades. Energy Build., 43(5), 1123-1138. http:// dx.doi.org/10.1016/j.enbuild.2010.08.031.

[11] Bianco L., Vigna I., Serra V. (2017), Experimental characterization of adaptive transparent façades: lessons learned from three case studies. In: Energy for Sustainability International Conference, 2017 Designing Cities \& Communities for the Future, no. February

[12] Waldner R., et al. (2007), Best Practice: Double Skin Façades.

[13] Hensen J., Bartak M., Drkal F. (2002), Modeling and simulation of a double-skin façade system. ASHRAE Trans., 108(2), 1251-1259. http://www.bwk.tue.nl/bps/hensen/ publications/02_ashrae_dskin.pdf

[14] De Gracia A., Castell A., Navarro L., Oró E., Cabeza L. F. (2013), Numerical modelling of ventilated facades: A review. Renew. Sustain. Energy Rev. 22, 539-549.

[15] EQUA Simulation AB, IDA Indoor Climate and Energy.

[16] Dubois M.-C., Horvat M. (eds) (2010), State-of-the-art of digital tools used by architects for solar design, IEA-SHC Programme Task 41. Sol. Energy Archit., 41, 19.

[17] International Organisation for Standardisation (2003), ISO 15099:2003 Thermal performance of windows, doors and shading devices - detailed calculations.

[18] EQUA Simulation AB (2013), EQUA Simulation AB User Manual IDA Indoor Climate and Energy. no. February, https://www.equa.se/deliv/ICE45eng.pdf

[19] EQUA Simulation AB, IDA - Indoor Climate and Energy ver 3.0 NMF-model documentation.

[20] VDI Heat Atlas. 2010. 